\title{
Evaluation of the Perception and Clinical Characteristics of Facial Skin Aging according to Age-group among Korean Women
}

\author{
Ki Bbeum Kim ${ }^{1,2}$, Ji Yea Kim ${ }^{1,2}$, Sungkwan $\mathrm{An}^{3}$, Eunseol Min ${ }^{4}$, Seunghee $\mathrm{Bae}^{3 *}$ \\ ${ }^{1}$ Department of Biological Engineering, Konkuk University, Seoul, Korea \\ ${ }^{2}$ Korea Institute of Dermatological Sciences, Seoul, Korea \\ ${ }^{3}$ Research Institute for Molecular-Targeted Drugs, Department of Cosmetics Engineering, Konkuk University, Seoul, Korea \\ ${ }^{4}$ Metafomula Co., Seongman-si, Gyeonggi-do, Korea
}

\section{Corresponding author: Seunghee Bae, Research Institute for Molecular- Targeted Drugs, Department of Cosmetics Engineering, Konkuk University, 120 Neungdong-ro, Gwangjin-gu, Seoul 05029, Korea}

Tel.: +82 24500463

Email: sbae@konkuk.ac.kr

Received July 19, 2019

Revised August 27, 2019

Accepted August 30, 2019

Published September 30, 2019

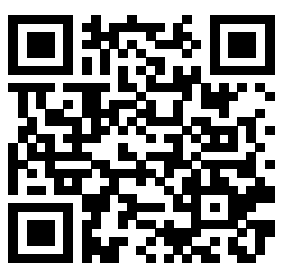

\begin{abstract}
Purpose: In this study, we tried to reveal the levels of the perception and clinical characteristics of facial skin aging among adult Korean women according to age. Methods: Using literature reviews, we determined the different levels of each facial skin aging sign is related to the chronological age of individuals, and developed the multiple-choice chart based on the four different levels; low, medium, high and very high. Forthy Korean participants were asked to describe their perceived levels of the aged signs using the chart. Also, clinical study was conducted to investigate the changes of the aged signs according to age-group among the participants. Results: We found that age-related structural changes on a human face were shown on the ten different regions, including wrinkles in the outer corner and bottom of eyes, wrinkles between the eyebrows, nasolabial lines, pigmentation and skin texture on cheeks, lip lines, sagging on a double chin, pore sizes on the nose, dark circles under the eyes. The survey results showed that the aged levels of all 10 categories were described to be increased as participant-age increases. To verify the results, we clinically tested whether the facial skin aging signs have a tendency to increase with the chronological age using an ANTERA-3D device, and found that the aged levels of the signs were specifically increased with the chronological age. Conclusion: Therefore, our results suggested that the perceived and clinical levels on the 10 regions of facial skin aging were relate to the chronological age.
\end{abstract}

Keywords: Facial skin, Aging, Perception, Age, Clinical study

\section{Introduction}

신체 중에서 피부는 가장 크고 복잡한 기관 중 하나이며, 여 러 세포와 층으로 구성되어 있다(Feng et al., 2019). 피부는 신 체의 내부와 외부 환경을 구분 짓는 구조적인 장벽능을 제공하고 있으며, 경피 수분 손실 억제, 온도 유지, 감각 지각, 면역 감시 (immune surveillance) 등의 다양한 생물학적 기능을 담당하고 있다(Farage et al., 2013). 뿐만 아니라, 피부 내외적 상태는 개 인의 자존감(self-esteem)과 사회적 활동에 중요한 역할을 하고 있다(Gupta \& Gilchrest, 2005).

피부 노화는 내인성 노화(intrinsic aging)와 외인성 노화 (extrinsic aging)로 개념화할 수 있다(Kim et al., 2018). 내인
성 노화는 역연령(chronological age)에 따라 모든 조직에서 나타 나는 자연스런 노화의 과정을 말하며(Pierard et al., 2014), 피 부 표면 거칠기, 잔 주름, 피부 위축 등이 증가하는 결과를 가져 온다(Edwards et al., 2003). 외인성 노화는 주로 자외선, 적외 선, 흡연, 오염 등의 외부적인 환경요인의 노출에 의해서 나타나 며, 내인성 노화를 가속화시킨다고 보고되고 있다(Guinot et al., 2002). 해당 요인의 빈번한 노출은 깊은 주름과 색소 침착 등의 결과를 초래한다(Yaar \& Gilchrest, 2007).

세부적으로 인간 피부는 해부학적인 위치에 따라 내인성 노화 와 외인성 노화가 동시에 일어 날 수 있다. 특히, 얼굴은 이러한 결과가 적용될 수 있는 대표적인 피부 부분으로, 다른 피부 부분 에 비해 일생동안 지속적으로 외부 환경에 노출되는 특징을 가진 
다(Delvenne et al., 2013). 게다가, 반복적인 얼굴 표정은 주름 의 생성을 악화시킬 수 있다(Lemperle et al., 2001). 얼굴 피부 의 겉모습은 나이를 인식하는데 가장 중요하게 작용한다(Geng et al., 2007; Coma et al., 2014). 서양 사회에서, 여성들은 얼굴에 나타나는 외모 및 가시적인 노화 현상에 대한 관심이 매우 높게 나타나며, 특히 화장품과 피부관리에 대한 비용 지출의 증가와 관 련 있다고 보고되었다(Twigg et al., 2014).

비록 수년동안 광범위한 연구가 진행되고 있으나, 인간 노화 에 대한 정확한 생물학적 마커(biological marker)는 없는 상태 이다(Sprott, 2010). 다양한 역연령은 생물학적 노화에 대한 가 장 대표적인 예측인자 중 하나로 여겨지고 있다. 이것은 또한 피 부 노화에도 연결될 수 있다. 피부학적 연구분야에 있어 생물학 적과 생물리학적 피부 특성을 평가하는 다양한 파라미터 들이 제 시되고 있다(Rogiers, 2001). 예를 들어, 피부 표면 $\mathrm{pH}$, 각질층 의 수분도(stratum corneum hydration, $\mathrm{SCH}$ ), 경피수분손실 (transepidermal water loss, TEWL)과 같은 기능학적 파라미터 들은 피부 장벽의 온전성(integrity)과 상태에 대한 마커로 활용되 고 있다(Rogiers, 2001). 상기 파라미터 등은 피부노화가 진행됨 에 따라, 피부 표면 $\mathrm{pH}$ 의 증가, TEWL 감소, 피부 표면 거칠기 증 가 및 피부 탄력 감소 등으로 나타난다(Kottner et al., 2013). 이 러한 노화 의존적인 변화는 피부 색에도 나타난다. 이러한 기계 적 측정을 기반으로 한 기능학적 파라미터와 더불어, 피부노화와 연관된 다양한 임상학적 지표들도 피부 연구 및 피부미용학에 사 용되고 있다. 주름, 색소침착, 피부 처짐 등은 피부 노화 정도를 판단하는데 중요한 임상지표로 사용된다(Trojahn et al., 2014; Masuda et al., 2014)

비록 많은 연구들은 얼굴에 나타나는 피부 노화 정도를 평가하 기 위하 상기 파라미터들을 적용하고 있으나, 임상학적 특징과 생 물리학적 파라미터 간의 관련성 유무 및 관련 정도에 대한 포괄적 인 연구 결과는 아직 정립되지 않았다. 최근 연구 논문은 신체 노 화를 판단하는데 기본이 되는 역연령은 얼굴에 나타나는 피부 노 화 증상 및 정도에 가장 중요하게 영향을 미치는 인자로 보고되었 다(Trojahn et al., 2015). 이는, 얼굴에 나타나는 피부 노화 증상 은 인간이 가지는 역연령과 관련성이 높다는 것이다.

생물학적으로 나이에 따른 피부노화가 진행됨에 따라, 피부 속 의 콜라겐의 양이 감소된다(Fu et al., 2010). 이러한 콜라겐의 감 소는 중력의 효과와 더불어 피부를 더욱 검게, 얇게, 덜 탄력있게 만든다. 또한, 지방세포 밀도가 감소함에 따라 피부의 처짐을 이 끈다 (Fu et al, , 2010). 이러한 다양한 피부 노화의 결과로 인해 얼굴 피부는 국소적인 색소침착과 주름 정도가 증가되는 방향으로 나타난다(Fu et al., 2010). 이러한 노화에 따른 얼굴 피부의 변화 는 피부 밑에 존재하는 골격 노화를 통해서도 가속화 된다고 보고 되었다. 즉, 나이에 따른 얼굴 피부의 노화는 내외부적인 요인에 따른 조직학적 변화와 골격적인 변화가 복합적으로 나타난다는 것
이다. 얼굴 피부의 노화에 있어 노화의 속도는 성인 연령에 따라 매우 다르게 나타나나, 특정 연령대에 보이는 노화의 속도가 증가 되는 현상이 피부에서 나타난다(Albert et al., 2007). 20대에서 30 대로 가면서 피부의 낮은 변화가 나타나나, 40 대에서 50 대로 가면서 가시적인 머리, 얼굴 그리고 목 부분의 피부 변화가 뚜렷 이 나타난다(Albert et al., 2007).

얼굴 피부의 노화에 있어 가장 뚜렷한 변화는 얼굴 내 주름과 피부 처짐이다. 얼굴에서 나타나는 주름은 다른 피부 보단 화장 품적과 피부과적 수술적으로 관심이 많은 부분이라, 얼굴에 나타 난 주름에 대한 분류가 진행되고 있다. Fitzpatrick은 얼굴에 나타 나는 주름을 정도에 따라 3 단계로 분류하였다(Fitzpatrick et al., 1996). 하지만, 본 분류법은 주름의 깊이 보다는 주름의 정도 및 피부 탄력 저하 정도에 따라 분류한 것이다. Glogau도 얼굴의 주 름을 3 단계로 분류하는 법을 제시하였으나, 잔주름 및 깊은 주름 에 대한 설명은 없었다(Glogau, 1996). Lemperle은 이러한 단점 을 극복하고자, 얼굴의 주름을 눈가, 볼, 입술주위, 미간, 이중턱, 목, 귀 등을 포함한 11 부분으로 세분화하여, 각 부분에 대한 주 름의 깊이를 5 단계로 정하는 법을 제시하였다(Lemperle et al., 2001).

상기 연구결과를 요약하자면, 얼굴의 노화 정도는 실제 연령에 따라 다르게 나타날 수 있다는 것을 의미하나, 얼굴에서 나타나는 주름 등의 피부 변화가 실제 연령과의 연관성 정도에 대한 연구는 아직 부족하다. 따라서, 본 논문에서는 이러한 얼굴에서 나타나 는 세부적인 주름에 대한 정도가 실제 연령별로 차이가 있는지를 검증하고자, 30 대에서 60 대 사이의 한국인 여성을 대상으로 얼굴 부분에서 나타나는 주름의 정도를 설문법과 임상측정을 통하여, 해당 정도와 실제 연령과의 관계성 유무를 파악하고자 하였다.

\section{Methods}

\section{1. 피시험자의 선정}

본 연구를 위해 30-69세의 신체질환이 없는 한국인 여성을 피 시험자로 선정하였으며, 연령별 안면 피부 상태를 측정하기위해, 30 대 피시험자 10 명, 40 대 피시험자 10 명, 50 대 피시험자 10 명, 60 대 피시험자 10 명을 대상으로 진행하였다. 본 실험은 한국피부 과학연구원 기간생명윤리위원회에 심사 후 연령별 안면 피부 상태 측정만 하는 연구로 관련 심의면제 대상임을 확인받았으며, 2019 년 2월 11일부터 2019년 3월 18일까지 진행하였다(과제관리번 호: 1-70005239-AB-N-01-2019-KIDS-AIA065-HR-01).

\section{2. 선다형을 이용한 피시험자의 안면 노화 상태 설문조사}

상기 Introduction에서 언급한 안면 노화 시 나타나는 주름 등 피부 변화에 대한 피시험자의 인식도를 조사하기 위해서, 안면 
내 세부 노화와 연관된 10 부분에 대한 정도를 바우만 피부타입 (Baumann, 2008) 내 주름과 관련한 문항을 선다형으로 제작하 여, 피시험자들에게 설문조사를 실시하였다. 설문 문항 및 각 문 항별 선다형은 Table 1 과 같다.

\section{3. 연령 변화에 따른 눈 밑 주름, 눈꼬리 주름, 미간 주름, 팔자 주 름 평가}

먼저, 피시험자의 정확한 피부 측정을 위해, 동일한 세안제 로 세안 후 $30 \mathrm{~min}$ 항온항습실에서 안정을 취하게 하였다. 이 후, ANTERA 3D (Miravex Co., Ltd, Dublin, Ireland)를 이용 하여, 연령 변화에 따른 눈 밑 주름, 눈꼬리 주름, 미간 주름, 팔 자 주름의 정도를 측정하였다. 측정된 이미지는 ANTERA CS software를 이용하여 분석하였으며, 측정값은 피부 주름을 평가 하는 Wrinkles 값을 이용하여 미세 주름은 small, 중간 주름은 medium, 굵은 주름은 large의 scale을 분석에 사용하였다.

\section{4. 연령 변화에 따른 안면 기미 평가}

피시험자의 안면 기미 정도를 평가하기 위해, 세안 후 $30 \mathrm{~min}$ 항온항습실에서 안정을 취하게 하였으며, ANTERA 3D를 이 용하여 피시험자의 안면 부분을 측정하였다. 측정된 이미지는 ANTERA CS software (Miravex Co., Ltd)를 이용하여 피부의 기미를 평가하는 멜라닌 값을 분석에 사용하였다.

\section{5. 통계분석}

본 시험을 통해 얻어진 결과값은 SPSS 17.0 for Windows (IBM, USA) 프로그램을 이용하여, 평균, 표준편차, 빈도, 백분율 을 산출하였으며, 측정값에 대한 유의성 판단은 paired $t$-test 분 석을 실시하여 검증하였다.

\section{Results and Discussion}

\section{1. 설문조사 기반 피시험자 주관적 안면 피부 노화 상태 결과}

얼굴은 신체 피부 중 외부 환경에 대한 노출이 빈번한 부분으 로, 얼굴에서 나타나는 노화의 정도를 통해 대중들은 그 사람의 나이(perceived facial age)를 예측한다고 알려져 있다(Trojahn et al., 2015). Caucasian 사람들을 대상으로 한 연구를 통 해, 얼굴을 통한 인지연령(perceived age)은 실질적인 나이(역 연령, chronological age)와 높은 연관성이 있다고 보고되었다 (Tsukahara et al., 2004). 특히, 인지연령과 밀접한 관계성을 보 이는 부분은 얼굴에 나타나는 주름의 정도로 알려져 있으며, 얼굴 의 주름의 정도는 역연령과 정비례 관계성을 갖는다(Tsukahara et al., 2007). 서양인들과 동일하게, 일본, 중국 그리고 태국의 여성을 대상으로 한 연구에서도, 얼굴을 통한 인지연령은 주름의 정도로 판단하는 특성이 있으며, 주름의 정도는 역연령과 높은 관
Table 1. Questionnaire configuration

\begin{tabular}{l}
\hline Research variables \\
The level of periorbital wrinkles \\
The level of under eye wrinkles \\
The level of glabellar frown wrinkles \\
The levels of nasolabial folds \\
The pigmentation levels on cheeks \\
The levels of lip lines \\
The level of sagging on a double chin \\
The level of smoothness on cheeks \\
The level of pore size on cheeks \\
The level of eye circle
\end{tabular}

계성이 있다고 나타냈다(Tsukahara et al., 2007). 얼굴 내 특히 눈가 주름의 정도는 나이의 증가와 정비례적인 관계성이 높은 수 치로 알려져 있다. 또한, 팔자 주름 등의 볼 부분의 주름의 정도 또한 나이에 따라 증가된다고 보고되었다. 여러 논문들을 통해, 얼굴 노화에 있어서 나이에 따라 증가되는 부분은 10 부분으로 요 약할 수 있으며, Table 1에 정리하였다. 이러한 얼굴의 노화 정도 를 통한 인지연령과 역연령은 정의 관계에 있다고 알려져 있으나, 한국인 여성을 대상으로 진행한 연구는 미미한 편이다. 따라서, 본 논문에서는 한국인 여성들을 대상으로, 30 대, 40 대, 50 대, 60 대별로 나타나는 안면 노화 인식도와 임상학적으로 연령별 안면 피부 노화 정도를 측정하고자 하였다.

우선, Table 1 에서 언급한 얼굴 내 10 부분에 대한 노화의 인식 도가 연령별로 어떠한 결과를 나타내는지 알아보았다. 30 대, 40 대, 50 대, 60 대 한국인 여성 10 명(총 40 명)을 대상으로, 본인의 얼굴에서 나타나는 노화 정도의 인식도를 평가하는데 있어, 주관 적인 평가 정도를 낮추고자, 2 가지 방식을 사용하였다. 첫 번째 는, 얼굴 내 세부 10 부분에 대한 노화의 정도를 4 수준으로 나누어 선택하게끔 하였으며, 두 번째는 photo scoring method (Mayes et al., 2010)을 기반으로, 얼굴 내 세부 부분에 대한 노화 정도 를 사진으로 보여주어 선택하게끔 하였다. 피부 노화를 측정하는 방법 중 하나는 정량 분석이며, 피부 표면의 굴곡도(topography) 및 인장력(displacement rate of skin surface)를 기반으로 한다 (Li et al., 2006; Endo et al., 2001). 하지만 본 방법은 안면 노 화의 인지도 분석에 있어 사용하기 힘들며, 젊은 나이대의 피부에 있어서 피부의 처짐 정도가 낮아 세분화하기 힘들다는 단점이 있 다. 최근 연구에 따르면, 노화에 따른 피부 표면 굴곡 변화는 50 대와 60 대의 피부에서만 증가한다고 알려져 있다(Mayes et al., 2010). Photo scoring methods는 피부 노화 연구를 진행하는데 있어 최근 많이 사용되는 방법으로, 카메라 이외에 피부 측정장 비가 필요하지 않아, 설문지 기반의 인식도 조사에 적절해, 피부 과, 성형외과, 화장품학에 많이 사용된다(Griffiths et al., 1992; Larnier et al., 1994; Lemperle et al., 2001).

선다형을 이용하여 30-60대 피시험자의 10부분에 대한 안면 
피부 노화 상태를 설문조사한 결과는 다음과 같다. 눈가 주름 상 태에 있어서 30 대는 '거의 주름이 보이지 않는다'가 50\%의 비율로 답하였으며, 40 대는 '미세한 가로형의 주름이 보인다'가 $40 \%$ 의 비 율로 답하였으며, 50 대는 '눈꼬리 옆에 부채형의 옅은 주름이 보 인다'가 $60 \%$ 의 비율로 답하였고, 60 대는 '눈꼬리 옆에 부채형으로 퍼진 깊은 주름이 보인다'가 $90 \%$ 의 비율로 답하였다 (Table 2).

눈 밑 주름 상태에 있어서 30대 및 40대는 '눈 아래 둥근 반원
형의 미세한 주름이 보인다'가 $80 \%$ 및 $70 \%$ 비율로 답하였으며, 50 대는 '눈 아래에 옅은 주름과 눈 앞머리에 처진듯한 주름이 보 인다'가 $70 \%$ 의 비율로 답하였고, 60 대는 '눈 아래에 진한 주름 과 눈 앞머리에 처진 주름이 보인다'가 $90 \%$ 의 비율로 답하였다 (Table 3).

미간 주름 상태에 있어서 30대 및 40대는 '미세한 가로형의 주 름이 보인다'가 $70 \%$ 및 $60 \%$ 비율로 답하였으며, 50 대는 '눈썹 사

Table 2. The survey results of periorbital wrinkles

\begin{tabular}{|c|c|c|c|c|c|c|c|c|}
\hline \multirow{2}{*}{ Scales } & \multicolumn{2}{|c|}{$30 \mathrm{~s}(\mathrm{~N}=10)$} & \multicolumn{2}{|c|}{$40 \mathrm{~s}(\mathrm{~N}=10)$} & \multicolumn{2}{|c|}{$50 \mathrm{~s}(\mathrm{~N}=10)$} & \multicolumn{2}{|c|}{$60 \mathrm{~s}(\mathrm{~N}=10)$} \\
\hline & Frequency & $\%$ & Frequency & $\%$ & Frequency & $\%$ & Frequency & $\%$ \\
\hline 1 (lowest) & 5 & 50.0 & 2 & 20.0 & 0 & 0.0 & 0 & 0.0 \\
\hline 2 & 3 & 30.0 & 4 & 40.0 & 2 & 20.0 & 0 & 0.0 \\
\hline 3 & 2 & 20.0 & 3 & 30.0 & 6 & 60.0 & 1 & 10.0 \\
\hline 4 (highest) & 0 & 0.0 & 1 & 10.0 & 2 & 20.0 & 9 & 90.0 \\
\hline
\end{tabular}

Table 3. The survey results of under eye wrinkles

\begin{tabular}{|c|c|c|c|c|c|c|c|c|}
\hline \multirow{2}{*}{ Scales } & \multicolumn{2}{|c|}{$30 \mathrm{~s}(\mathrm{~N}=10)$} & \multicolumn{2}{|c|}{$40 \mathrm{~s}(\mathrm{~N}=10)$} & \multicolumn{2}{|c|}{$50 \mathrm{~s}(\mathrm{~N}=10)$} & \multicolumn{2}{|c|}{$60 \mathrm{~s}(\mathrm{~N}=10)$} \\
\hline & Frequency & $\%$ & Frequency & $\%$ & Frequency & $\%$ & Frequency & $\%$ \\
\hline 1 (lowest) & 1 & 10.0 & 0 & 0.0 & 0 & 0.0 & 0 & 0.0 \\
\hline 2 & 8 & 80.0 & 7 & 70.0 & 3 & 30.0 & 1 & 10.0 \\
\hline 3 & 1 & 10.0 & 3 & 30.0 & 7 & 70.0 & 9 & 90.0 \\
\hline 4 (highest) & 0 & 0.0 & 0 & 0.0 & 0 & 0.0 & 0 & 0.0 \\
\hline
\end{tabular}

Table 4. The survey results of glabellar frown wrinkles

\begin{tabular}{|c|c|c|c|c|c|c|c|c|}
\hline \multirow{2}{*}{ Scales } & \multicolumn{2}{|c|}{$30 \mathrm{~s}(\mathrm{~N}=10)$} & \multicolumn{2}{|c|}{$40 s(N=10)$} & \multicolumn{2}{|c|}{$50 s(N=10)$} & \multicolumn{2}{|c|}{$60 s(N=10)$} \\
\hline & Frequency & $\%$ & Frequency & $\%$ & Frequency & $\%$ & Frequency & $\%$ \\
\hline 1 (lowest) & 1 & 10.0 & 1 & 10.0 & 0 & 0.0 & 0 & 0.0 \\
\hline 2 & 7 & 70.0 & 6 & 60.0 & 1 & 10.0 & 1 & 10.0 \\
\hline 3 & 2 & 20.0 & 3 & 30.0 & 7 & 70.0 & 1 & 10.0 \\
\hline 4 (highest) & 0 & 0.0 & 0 & 0.0 & 2 & 20.0 & 8 & 80.0 \\
\hline
\end{tabular}

Table 5. The survey results of nasolabial folds

\begin{tabular}{|c|c|c|c|c|c|c|c|c|}
\hline \multirow{2}{*}{ Scales } & \multicolumn{2}{|c|}{$30 \mathrm{~s}(\mathrm{~N}=10)$} & \multicolumn{2}{|c|}{$40 \mathrm{~s}(\mathrm{~N}=10)$} & \multicolumn{2}{|c|}{$50 \mathrm{~s}(\mathrm{~N}=10)$} & \multicolumn{2}{|c|}{$60 \mathrm{~s}(\mathrm{~N}=10)$} \\
\hline & Frequency & $\%$ & Frequency & $\%$ & Frequency & $\%$ & Frequency & $\%$ \\
\hline 1 (lowest) & 0 & 0.0 & 0 & 0.0 & 0 & 0.0 & 0 & 0.0 \\
\hline 2 & 7 & 70.0 & 4 & 40.0 & 2 & 20.0 & 0 & 0.0 \\
\hline 3 & 3 & 30.0 & 6 & 60.0 & 5 & 50.0 & 4 & 40.0 \\
\hline 4 (highest) & 0 & 0.0 & 0 & 0.0 & 3 & 30.0 & 6 & 60.0 \\
\hline
\end{tabular}

Table 6. The survey results of pigmentation levels on cheeks

\begin{tabular}{|c|c|c|c|c|c|c|c|c|}
\hline \multirow{2}{*}{ Scales } & \multicolumn{2}{|c|}{$30 \mathrm{~s}(\mathrm{~N}=10)$} & \multicolumn{2}{|c|}{$40 \mathrm{~s}(\mathrm{~N}=10)$} & \multicolumn{2}{|c|}{$50 \mathrm{~s}(\mathrm{~N}=10)$} & \multicolumn{2}{|c|}{$60 \mathrm{~s}(\mathrm{~N}=10)$} \\
\hline & Frequency & $\%$ & Frequency & $\%$ & Frequency & $\%$ & Frequency & $\%$ \\
\hline 1 (lowest) & 0 & 0.0 & 0 & 0.0 & 1 & 10.0 & 0 & 0.0 \\
\hline 2 & 10 & 100.0 & 5 & 50.0 & 7 & 70.0 & 1 & 10.0 \\
\hline 3 & 0 & 0.0 & 5 & 50.0 & 2 & 20.0 & 2 & 20.0 \\
\hline 4 (highest) & 0 & 0.0 & 0 & 0.0 & 0 & 0.0 & 7 & 70.0 \\
\hline
\end{tabular}


이에 가로형과 세로형의 옅은 주름이 보인다'가 $70 \%$ 의 비율로 답 하였고, 60 대는 '눈썹 사이에 가로형과 세로형의 깊은 주름이 보 인다'가 $80 \%$ 의 비율로 답하였다 (Table 4).

팔자 주름 상태에 있어서 30 대는 '옅은 팔자 주름의 형태가 보 인다'가 $70 \%$ 의 비율로 답하였으며, 40 대와 50 대에서는 '비교적 뚜렷한 팔자 주름이 보인다'가 $60 \%$ 및 $50 \%$ 의 비율로 답하였으며, 60 대는 '콧방울 옆으로 시작하여 입꼬리까지 이어지는 깊은 팔자
주름이 보인다'가 $60 \%$ 의 비율로 답하였다 (Table 5).

볼 부위 색소침착 상태에 있어서 30 대, 40 대 및 50 대가 '볼광대 부위에 옅은 색소침착이 군데군데 보인다'가 $100 \%, 50 \%, 70 \%$ 로 답하였으며, 60 대는 '비교적 넓은 부위에 색소침착 면적과 함께 짙은 기미 자국이 보인다'가 70\%의 비율로 답하였다 (Table 6).

입술 주름 상태에 있어서, 30 대 및 50대는 '잔주름이 조금 보이 는 편이다'가 $70 \%$ 및 $60 \%$ 의 비율로 답하였으며, 40 대는 '굵은 주

Table 7. The survey results of lip lines

\begin{tabular}{|c|c|c|c|c|c|c|c|c|}
\hline \multirow{2}{*}{ Scales } & \multicolumn{2}{|c|}{$30 \mathrm{~s}(\mathrm{~N}=10)$} & \multicolumn{2}{|c|}{$40 \mathrm{~s}(\mathrm{~N}=10)$} & \multicolumn{2}{|c|}{$50 \mathrm{~s}(\mathrm{~N}=10)$} & \multicolumn{2}{|c|}{$60 \mathrm{~s}(\mathrm{~N}=10)$} \\
\hline & Frequency & $\%$ & Frequency & $\%$ & Frequency & $\%$ & Frequency & $\%$ \\
\hline 1 (lowest) & 0 & 0.0 & 0 & 0.0 & 0 & 0.0 & 0 & 0.0 \\
\hline 2 & 7 & 70.0 & 3 & 30.0 & 6 & 60.0 & 0 & 0.0 \\
\hline 3 & 3 & 30.0 & 6 & 60.0 & 4 & 40.0 & 5 & 50.0 \\
\hline 4 (highest) & 0 & 0.0 & 1 & 10.0 & 0 & 0.0 & 5 & 50.0 \\
\hline
\end{tabular}

Table 8. The survey results of sagging on a double chin

\begin{tabular}{|c|c|c|c|c|c|c|c|c|}
\hline \multirow{2}{*}{ Scales } & \multicolumn{2}{|c|}{$30 \mathrm{~s}(\mathrm{~N}=10)$} & \multicolumn{2}{|c|}{$40 \mathrm{~s}(\mathrm{~N}=10)$} & \multicolumn{2}{|c|}{$50 \mathrm{~s}(\mathrm{~N}=10)$} & \multicolumn{2}{|c|}{$60 \mathrm{~s}(\mathrm{~N}=10)$} \\
\hline & Frequency & $\%$ & Frequency & $\%$ & Frequency & $\%$ & Frequency & $\%$ \\
\hline 1 (lowest) & 6 & 60.0 & 0 & 0.0 & 2 & 20.0 & 0 & 0.0 \\
\hline 2 & 4 & 40.0 & 4 & 40.0 & 3 & 30.0 & 1 & 10.0 \\
\hline 3 & 0 & 0.0 & 5 & 50.0 & 5 & 50.0 & 3 & 30.0 \\
\hline 4 (highest) & 0 & 0.0 & 1 & 10.0 & 0 & 0.0 & 6 & 60.0 \\
\hline
\end{tabular}

Table 9. The survey results of smoothness on cheek

\begin{tabular}{|c|c|c|c|c|c|c|c|c|}
\hline \multirow{2}{*}{ Scales } & \multicolumn{2}{|c|}{$30 \mathrm{~s}(\mathrm{~N}=10)$} & \multicolumn{2}{|c|}{$40 \mathrm{~s}(\mathrm{~N}=10)$} & \multicolumn{2}{|c|}{$50 \mathrm{~s}(\mathrm{~N}=10)$} & \multicolumn{2}{|c|}{$60 \mathrm{~s}(\mathrm{~N}=10)$} \\
\hline & Frequency & $\%$ & Frequency & $\%$ & Frequency & $\%$ & Frequency & $\%$ \\
\hline 1 (lowest) & 1 & 10.0 & 0 & 0.0 & 0 & 0.0 & 0 & 0.0 \\
\hline 2 & 3 & 30.0 & 6 & 60.0 & 4 & 40.0 & 1 & 10.0 \\
\hline 3 & 3 & 30.0 & 4 & 40.0 & 4 & 40.0 & 3 & 30.0 \\
\hline 4 (highest) & 3 & 30.0 & 0 & 0.0 & 2 & 20.0 & 6 & 60.0 \\
\hline
\end{tabular}

Table 10. The survey results of pore size on cheeks

\begin{tabular}{|c|c|c|c|c|c|c|c|c|}
\hline \multirow{2}{*}{ Scales } & \multicolumn{2}{|c|}{$30 \mathrm{~s}(\mathrm{~N}=10)$} & \multicolumn{2}{|c|}{$40 \mathrm{~s}(\mathrm{~N}=10)$} & \multicolumn{2}{|c|}{$50 \mathrm{~s}(\mathrm{~N}=10)$} & \multicolumn{2}{|c|}{$60 \mathrm{~s}(\mathrm{~N}=10)$} \\
\hline & Frequency & $\%$ & Frequency & $\%$ & Frequency & $\%$ & Frequency & $\%$ \\
\hline 1 (lowest) & 0 & 0.0 & 0 & 0.0 & 0 & 0.0 & 0 & 0.0 \\
\hline 2 & 2 & 20.0 & 3 & 30.0 & 4 & 40.0 & 1 & 10.0 \\
\hline 3 & 7 & 70.0 & 5 & 50.0 & 6 & 60.0 & 2 & 20.0 \\
\hline 4 (highest) & 1 & 10.0 & 2 & 20.0 & 0 & 0.0 & 7 & 70.0 \\
\hline
\end{tabular}

Table 11. The survey results of eye circle

\begin{tabular}{|c|c|c|c|c|c|c|c|c|}
\hline \multirow{2}{*}{ Scales } & \multicolumn{2}{|c|}{$30 \mathrm{~s}(\mathrm{~N}=10)$} & \multicolumn{2}{|c|}{$40 \mathrm{~s}(\mathrm{~N}=10)$} & \multicolumn{2}{|c|}{$50 \mathrm{~s}(\mathrm{~N}=10)$} & \multicolumn{2}{|c|}{$60 \mathrm{~s}(\mathrm{~N}=10)$} \\
\hline & Frequency & $\%$ & Frequency & $\%$ & Frequency & $\%$ & Frequency & $\%$ \\
\hline 1 (lowest) & 1 & 10.0 & 1 & 10.0 & 1 & 10.0 & 0 & 0.0 \\
\hline 2 & 4 & 40.0 & 6 & 60.0 & 6 & 60.0 & 1 & 10.0 \\
\hline 3 & 4 & 40.0 & 3 & 30.0 & 2 & 20.0 & 3 & 30.0 \\
\hline 4 (highest) & 1 & 10.0 & 0 & 0.0 & 1 & 10.0 & 6 & 60.0 \\
\hline
\end{tabular}


름이 보이는 편이다'가 $60 \%$ 의 비율로 답하였고, 60 대에서는 '입술 과 입술주위 모두 굵은 주름이 존재하다'가 $50 \%$ 의 비율로 답하였 다(Table 7).

이중턱의 피부 늘어짐 상태에 있어서 30 대는 '거의 처지지 않았 다'가 $60 \%$ 의 비율로 답하였으며, 40 대 및 50 대는 '처진 편이며 육 안상으로 이중턱이 살짝 불룩해 보인다'가 $50 \%$ 및 $50 \%$ 의 비율로 답하였고, 60 대는 '턱아래 부분에 처진 이중턱이 보인다'가 $60 \%$ 의 비율로 답하였다(Table 8).

안면 볼부위 피부결 상태에 있어서 30 대 및 40대는 '피부결이 느슨하고 늘어져 보인다'가 $30 \%$ 및 $60 \%$ 로 답하였으며, 50 대에는 '피부결이 늘어지고 푸석한 편이다'가 $40 \%$ 로 답하였고, 60 대에는 '색소침착과 함께 피부결이 늘어지고 푸석한 편이다'가 $60 \%$ 의 비 율로 답하였다(Table 9).

코 옆 볼부위의 모공 상태에 있어서, 30 대, 40 대, 50 대는 '부분 적으로 모공이 크게 육안으로 보인다'가 $70 \%, 50 \%, 60 \%$ 의 비율 로 답하였으며, 60 대에는 '모공이 비교적 크고 팔자 주름을 따라 모공이 처졌다'가 $70 \%$ 의 비율로 답하였다(Table 10).
마지막으로 눈 아래 다크서클 상태에 있어서, 30대, 40대, 50 대는 '연하게 잿빛 또는 갈색빛의 다크서클이 보인다'가 $40 \%$, $60 \%, 60 \%$ 로 답하였으며, 60 대에는 '진한 다크서클이 보인다'가 $60 \%$ 의 비율로 답하였다(Table 11).

\section{ANTERA 3D 측정기를 통한 피시험자의 연령에 따른 눈 밑 주 름, 눈꼬리 주름, 미간 주름, 팔자 주름 평가 결과}

ANTERA $3 \mathrm{D}$ 를 이용한 연령 변화에 따른 눈 밑 주름을 평가 한 결과는 다음과 같다(Table 12). ANTERA $3 \mathrm{D}$ 를 이용하여 눈 및 주름 부위를 분석한 결과, 피부의 주름을 평가하는 wrinkles medium 값이 30 대에서 $14.56,40$ 대에서 $17.38,50$ 대에서 $18.07,60$ 대에서 18.52 로 연령 증가에 따라 눈 밑 주름값이 증가 하였다.

ANTERA $3 \mathrm{D}$ 를 이용한 연령 변화에 따른 눈꼬리 주름을 평가 한 결과는 다음과 같다(Table 13 ). ANTERA $3 \mathrm{D}$ 를 이용하여 눈꼬 리 주름 부위를 분석한 결과, 피부의 주름을 평가하는 wrinkles small 값이 30 대에서 $6.78,40$ 대에서 $9.15,50$ 대에서 $11.35,60$

Table 12. The results of wrinkles medium value on under eye

\begin{tabular}{lcccc}
\hline & $30 \mathrm{~s}(\mathrm{~N}=10)$ & $40 \mathrm{~s}(\mathrm{~N}=10)$ & $50 \mathrm{~s}(\mathrm{~N}=10)$ & $60 \mathrm{~s}(\mathrm{~N}=10)$ \\
Mean & 14.56 & 17.38 & 18.07 & 18.52 \\
S.D. & 2.64 & 4.44 & 2.94 & 4.46 \\
\hline
\end{tabular}

S.D., standard deviation.

Table 13. The results of wrinkles small value on periorbital skin

\begin{tabular}{lcccc}
\hline & $30 \mathrm{~s}(\mathrm{~N}=10)$ & $40 \mathrm{~s}(\mathrm{~N}=10)$ & $50 \mathrm{~s}(\mathrm{~N}=10)$ & $60 \mathrm{~s}(\mathrm{~N}=10)$ \\
Mean & 6.78 & 9.15 & 11.35 & 13.30 \\
S.D. & 0.33 & 1.35 & 1.61 & 2.14 \\
\hline
\end{tabular}

S.D., standard deviation.

Table 14. The results of wrinkles medium value on glabellar frown

\begin{tabular}{lcccc}
\hline & $30 \mathrm{~s}(\mathrm{~N}=10)$ & $40 \mathrm{~s}(\mathrm{~N}=10)$ & $50 \mathrm{~s}(\mathrm{~N}=10)$ & $60 \mathrm{~s}(\mathrm{~N}=10)$ \\
Mean & 17.44 & 21.35 & 26.37 & 31.74 \\
S.D. & 3.97 & 5.59 & 5.39 & 12.28 \\
\hline
\end{tabular}

S.D., standard deviation.

Table 15. The results of wrinkles medium value on nasolabial folds

\begin{tabular}{lcccc}
\hline & $30 \mathrm{~s}(\mathrm{~N}=10)$ & $40 \mathrm{~s}(\mathrm{~N}=10)$ & $50 \mathrm{~s}(\mathrm{~N}=10)$ & $60 \mathrm{~s}(\mathrm{~N}=10)$ \\
Mean & 21.91 & 29.38 & 37.77 & 42.66 \\
S.D. & 4.98 & 7.11 & 11.13 & 13.24 \\
\hline
\end{tabular}

S.D., standard deviation.

Table 16. The results of melanin value on cheeks

\begin{tabular}{lcccc}
\hline & $30 \mathrm{~s}(\mathrm{~N}=10)$ & $40 \mathrm{~s}(\mathrm{~N}=10)$ & $50 \mathrm{~s}(\mathrm{~N}=10)$ & $60 \mathrm{~s}(\mathrm{~N}=10)$ \\
Mean & 0.570 & 0.620 & 0.660 & 0.665 \\
S.D. & 0.043 & 0.068 & 0.048 & 0.047 \\
\hline
\end{tabular}

S.D., standard deviation. 
대에서 13.30 으로 연령 증가에 따라 눈꼬리 주름값이 증가하였다.

$\mathrm{ANTERA} 3 \mathrm{D}$ 를 이용한 연령 변화에 따른 미간 주름을 평가한 결과는 다음과 같다(Table 14). ANTERA 3D를 이용하여 미간 부 위를 분석한 결과, 피부의 주름을 평가하는 wrinkles medium 값 이 30 대에서 $17.44,40$ 대에서 $21.35,50$ 대에서 $26.37,60$ 대에 서 31.74로 연령 증가에 따라 미간 주름값이 증가하였다.

ANTERA $3 \mathrm{D}$ 를 이용한 연령 변화에 따른 팔자 주름을 평가한 결과는 다음과 같다(Table 15). ANTERA 3D를 이용하여 팔자 부 위를 분석한 결과, 피부의 주름을 평가하는 Wrinkles large 값이 30 대에서 $21.91,40$ 대에서 $29.38,50$ 대에서 $37.77,60$ 대에서 42.66로 연령 증가에 따라 팔자 주름값이 증가하였다.

ANTERA $3 \mathrm{D}$ 를 이용한 연령 변화에 따른 기미를 평가한 결과 는 다음과 같다(Table 16). ANTERA 3D를 이용하여 볼광대부위 를 분석한 결과, 피부의 기미를 평가하는 melanin 값이 30 대에서 $0.570,40$ 대에서 $0.620,50$ 대에서 $0.660,60$ 대에서 0.665 로 연 령 증가에 따라 기미값이 증가하였다.

\section{Conclusion}

본 논문에서는 한국인 여성을 대상으로 연령별로 안면 부분에 서 나타나는 노화 정도에 대한 인식과 실제 임상학적 노화의 정도 에 대한 관계성에 대해서 연구하였다. Photo scoring methods를 기반으로 안면 노화 정도 인식에 대한 설문 조사를 통해, 연령별 로 안면 노화가 증가됨이 나타났으며, 피부 측정기를 통해 눈 밑 주름, 눈꼬리 주름, 볼 부위 기미, 팔자 주름, 미간 주름의 정도가 연령과 정비례의 관계에 있음을 입증하였다. 따라서, 본 연구결과 는 연령에 따른 안면노화 정도를 평가 및 예측하는데 중요한 학술 적 가치가 있다고 사료된다. 또한, 본 연구결과를 통해 연령에 대 한 피부노화의 인식 정도는 나이와 관계성이 높다는 것을 알 수 있으며, 연령별 안면 세부 부위의 노화 정도 증가는 추후 피부 나 이 평가를 기반한 개인 맞춤형 화장품 개발과 임상학적 피부관리 평가에 중요한 학문적인 참고로 활용될 수 있을 것으로 사료된다.

\section{Acknowledgements}

본 연구는 (주)메타포물러의 연구용역사업 지원에 의한 연구임.

\section{References}

Albert AM, Ricanek K Jr, Patterson E. A review of the literature on the aging adult skull and face: implications for forensic science research and applications. Forensic Science International, 172: 1-9, 2007.
Baumann L. Understanding and treating various skin types: the Baumann skin indicator. Dermatologic Cinics, 26: 359-373, 2008.

Coma M, Valls R, Mas JM, Pujol A, Herranz MA, Alonso V, Naval J. Methods for diagnosing perceived age on the basis of an ensemble of phenotypic features. Clinical, Cosmetic and Investigational Dermatology, 7: 133-137, 2014.

Delvenne M, Piérard-Franchimont C, Seidel L, Albert A, Piérard GE. The weather-beaten dorsal hand clinical rating, shadow casting optical profilometry, and skin capacitance mapping. BioMed Research International, 2013: 913646, 2013.

Edwards C, Heggie R, Marks R. A study of differences in surface roughness between sun-exposed and unexposed skin with age. Photodermatology Photoimmunology and Photomedicine, 19: 169-174, 2003.

Endo N, Nishijima T, Fujimura T, Moriwaki S, Takema Y. The methods of evaluation for facial sag by the analysis of topography around nasolabial groove. Journal of Society of Cosmetic Chemists of Japan, 35: 219-23, 2001.

Farage MA, Miller KW, Elsner P, Maibach HI. Characteristics of the aging skin. Advanced in Wound Care, 2: 5-10, 2013.

Feng F, Ma L, Qu Z, Dong Y, Yi F. Effects of skin surface lipids on skin health. Asian Journal of Beauty and Cosmetology, 17: 149-155, 2019.

Fitzpatrick RE, Goldman MP, Satur NM, Tope WD. Pulsed carbon dioxide laser resurfacing of photo-aged facial skin. Archives of Dermatology, 132: 395-402, 1996.

Fu Y, Guo G, Huang TS. Age synthesis and estimation via faces: a survey. IEEE Transactions on Pattern Analysis and Machine Intelligence, 32: 1955-1976, 2010.

Geng X, Zhou ZH, Smith-Miles K. Automatic age estimation based on facial aging patterns. IEEE Transactions on Pattern Analysis and Machine Intelligence, 29: 22342240, 2007.

Glogau RG. Aesthetic and anatomic analysis of the aging skin. Seminars in Cutaneous Medicine and Surgery, 15: 134-138, 1996.

Griffiths CE, Wang TS, Hamilton TA, Voorhees JJ, Ellis CN. A photonumeric scale for the assessment of cutaneous photodamage. Archives of Dermatology, 128: 347-351, 
1992.

Guinot C, Malvy DJ, Ambroisine L, Latreille J, Mauger E, Tenenhaus M, Morizot F, Lopez S, Le Fur I, Tschachler E. Relative contribution of intrinsic vs extrinsic factors to skin aging as determined by a validated skin age score. Archives of Dermatology, 138: 1454-1460, 2002.

Gupta MA, Gilchrest BA. Psychosocial aspects of aging skin. Dermatologic Clinics, 23: 643-648, 2005.

Kim JY, Bae S, Jung J, An S, An IS, Kim YS. Effects of Coptis chinensis extracts on matrix mellaproteinase-1 suppression through JNK/AP-1 axis in human dermal fibroblasts. Asian Journal of Beauty and Cosmetology, 16: 427-435, 2018.

Kottner J, Lichterfeld A, Blume-Peytavi U. Transepidermal water loss in young and aged healthy humans: a systematic review and meta-analysis. Archives of Dermatological Research, 305: 315-323, 2013.

Larnier C, Ortonne JP, Venot A, Faivre B, Béani JC, Thomas P, Brown TC, Sendagorta E. Evaluation of cutaneous photodamage using a photographic scale. British Journal of Dermatology, 130: 167-173, 1994.

Lemperle G, Holmes RE, Cohen SR, Lemperle SM, Fagien S. A classification of facial wrinkles. Plastic and Reconstructive Surgery, 108: 1735-1752, 2001.

Li L, Mac-Mary S, Marsaut D, Sainthillier JM, Nouveau S, Gharbi T, de Lacharriere O, Humbert P. Age-related changes in skin topography and microcirculation. Archives of Dermatological Research, 297: 412-416, 2006.

Masuda Y, Oguri M, Morinaga T, Hirao T. Three-dimensional morphological characterization of the skin surface micro-topography using a skin replica and changes with age. Skin Research and Technology, 20: 299-306, 2014.

Mayes AE, Murray PG, Gunn DA, Tomlin CC, Catt SD, Wen YB, Zhou LP, Wang HQ, Catt M, Granger SP. Ageing appearance in China: biophysical profile of facial skin and its relationship to perceived age. Journal of the
European Academy of Dermatology and Venereology, 24: 341-348, 2010.

Pierard GE, Charlier C, Delvenne P, Humbert P, PierardFranchimont C. Women's skin throughout lifetime. BioMed Research International, 2014: 328981, 2014.

Rogiers V. EEMCO guidance for the assessment of transepidermal water loss in cosmetic sciences. Skin Pharmacology and Applied Skin Physiology, 14: 117128, 2001.

Sprott RL. Biomarkers of aging and disease: introduction and definitions. Experimental Gerontology, 45: 2-4, 2010.

Trojahn C, Dobos G, Schario M, Ludriksone L, BlumePeytavi U, Kottner J. Relation between skin microtopography, roughness, and skin age. Skin Research and Technology, 21: 69-75, 2014.

Trojahn C, Dobos G, Lichterfeld A, Blume-Peytavi U, Kottner J. Characterizing facial skin ageing in humans: disentangling extrinsic from intrinsic biological phenomena. BioMed Research International, 2015: 318586, 2015.

Tsukahara K, Fujimura T, Yoshida Y, Kitahara T, Hotta M, Moriwaki S, Witt PS, Simion FA, Takema Y. Comparison of age-related changes in wrinkling and sagging of the skin in Caucasian females and in Japanese females. Journal of Cosmetic Science, 55: 373-385, 2004.

Tsukahara K, Sugata K, Osanai O, Ohuchi A, Miyauchi Y, Takizawa M, Hotta M, Kitahara T. Comparison of agerelated changes in facial wrinkles and sagging in the skin of Japanese, Chinese and Thai women. Journal of Dermatological Science, 47: 19-28, 2007.

Twigg J, Majima S. Consumption and the constitution of age: expenditure patterns on clothing, hair and cosmetics among post-war 'baby boomers'. Journal of Aging Studies, 30: 23-32, 2014.

Yaar M, Gilchrest BA. Photoageing: mechanism, prevention and therapy. The British Journal of Dermatology, 157: 874-887, 2007. 


\section{국문초록}

\section{한국 성인 여성의 연령별 얼굴 노화 정도에 대한 인식과 임상학적 특성에 관한 연구}

김기쁨 ${ }^{1,2}$, 김지예 ${ }^{1,2}$, 안성관 ${ }^{3}$, 민은설 ${ }^{4}$, 배승희 ${ }^{3 *}$

${ }^{1}$ 건국대학교 생물공학과, 서울, 한국

${ }^{2}$ 한국피부과학연구원, 서울, 한국

${ }^{3}$ 건국대학교 화장품공학과 질병분자표적신약연구소, 서울, 한국

${ }^{4}($ 주 $)$ 메타포뮬러, 경기도 성남시, 한국

목적: 본 논문에서는 한국인 여성들을 대상으로 연령별로 나타나는 얼굴 노화 정도에 대한 인식과 임상학적 특성을 밝히고자 하였 다. 방법: 참고문헌 조사를 통해, 얼굴에서 나타나는 노화의 세부 부분 및 정도를 결정하였다. 이를 기반으로, 4 지선다 형식의 설문 지를 개발하였으며, 각 부분에서 나타나는 노화의 정도를 4 수준(낮음, 중간, 높음, 아주 높음)으로 구분하게 하였다. 40 명의 한국인 여성을 대상으로 본인이 가지는 얼굴에 대한 노화 인식 정도를 설문지를 통해 측정하였다. 또한, 얼굴 노화 인식과 실제 연령별 피 부 노화 정도와의 관계성을 알아보기 위해, 임상학적 측정을 통해 관찰하였다. 결과: 참고문헌 조사를 통해 나이가 증가함에 딸 얼 굴에 나타나는 노화는 세부적으로 10 부분(눈 밑 주름, 눈꼬리 주름, 미간 주름, 팔자 주름, 볼 부위 기미, 볼 부위 피부톤, 입술 주름, 이중턱 부위의 피부 처짐, 눈 밑 다크서클, 코 옆 부위의 모공 크기) 에서 나타남을 알았다. 설문조사를 통한 얼굴 노화 정도에 대한 인식을 평가한 결과, 10 부분 모든 항목 내 노화의 정도와 평가자의 연령대가 비례적인 관계로 나타났다. 이러한 결과를 바탕으로, 얼굴의 노화 정도와 실제 나이와의 연관성을 임상학적으로 증명하고자, 평가자의 얼굴 내 노화 정도를 ANTERA-3D 측정기기를 이용하여 측정하였으며, 연령대가 증가할 수록 얼굴 내 세부 노화 정도도 비례적으로 증가함을 보였다. 결론: 따라서, 본 연구 결과 는 노화가 진행되면서 나타나는 얼굴 내 세부적인 10 부분에 대한 노화 정도 인식 및 임상학적 특성은 연령에 따라 증가함을 나타낸 다.

핵심어: 얼굴 피부, 노화, 인식, 나이, 임상학적 평가

본 연구는 (주)메타포물러의 연구용역사업 지원에 의한 연구임.

\section{참고문헌}

김지예, 배승희, 정진혁, 안성관, 안인숙, 김영삼. Coptis chinensis 추출물의 JNK/AP1 Axis을 통한 인간진피섬유아세포 내 MMP1 발현 억제 효능. 아시안뷰티화장품학술지, 16: 427-435, 2018.

풍법청, 마래기, 곡조휘, 동은묘, 역범. 피부 표면 지질과 피부 건강과의 관계. 아시안뷰티화장품학술지, 17: 149-155, 2019. 


\section{中文摘要}

\section{韩国女性按年龄组评估面部皮肤老化的感知和临床特征}

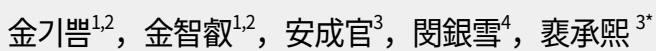

建国大学生物工学科, 首尔, 韩国

2韩国皮肤科学院, 首尔, 韩国

3建国大学化妆品学科疾病分子靶标新药研究所, 首尔, 韩国

${ }^{4}$ MetaFormula, 京畿道城南市, 韩国

目的: 在这项研究中，我们试图根据年龄显示成年韩国女性面部皮肤老化的感知水平和临床特征。方法: 利用文 献综述，确定每个面部皮肤老化征的不同水平与个体的实际年龄有关，并根据四个不同的水平制定多项选择图; 低, 中, 高和非常高。有意向的韩国参与者被要求使用图表描述他们对老年人体征的感知水平。此外, 进行了 临床研究以调查参与者中根据年龄组的老年体征的变化。结果: 我们发现人脸上与年龄相关的结构变化显示在 十个不同的区域, 包括眼角外侧和眼底皱纹, 眉毛之间的皱纹, 鼻唇沟线, 色素沉着和脸项上的皮肤纹理, 唇 线, 双下巴下垂, 鼻子上的毛孔, 眼睛下方的黑眼圈。调查结果显示, 随着参与者年龄的增加, 所有 10 个类别 的老年人水平都有所增加。为了验证结果，我们临床测试了面部皮肤老化迹象是否有使用ANTERA-3D装置随着 实际年龄增加的趋势, 并且发现老化的体征水平随着实际年龄而特别增加。结论: 因此, 我们的研究结果表明, 面部皮肤老化的10个区域的感知和临床水平与实际年龄有关。

关键词: 面部皮肤, 衰老, 感知, 年龄, 临床研究 